\title{
MATERNAL STATUS ELICITS DIFFERENTIAL RESPONSES TO WARMING IN FIDDLER CRABS
}

\author{
Pardo, J.C.F. ${ }^{1,2,}$; Cannicci, S. ${ }^{3}$; Jimenez, P.J. ${ }^{3}$; Granado, P. ${ }^{4} \&$ Costa, T.M. ${ }^{1,2}$ \\ ${ }^{1}$ Universidade Estadual Paulista (UNESP), Instituto de Biociências, Campus do Litoral Paulista, \\ Laboratório de Ecologia e Comportamento Animal (LABECOM). \\ ${ }^{2}$ Universidade Estadual Paulista (UNESP), Instituto de Biociências, Campus de Botucatu, \\ Programa de Pós-graduação em Ciências Biológicas (Zoologia). \\ ${ }^{3}$ The University of Hong Kong (HKU), The Swire Institute of Marine Science, School of Biological Sciences. \\ ${ }^{4}$ Universidade Federal de São Paulo (IMar/UNIFESP), Instituto do Mar. \\ *Corresponding author: pardojcf@yahoo.com.br
}

Coastal and estuarine ectotherms are potentially vulnerable to temperature instability, with their thermal tolerance varying among taxa and life-stages. Marine embryos and larvae are recognized as potentially vulnerable stages; however, the thermal sensitivity of ovigerous females it is still unexplored. The physio-behavioural changes in females with extruded eggs may carry consequences for the ovigerous female itself in a warming context, since it is a high energy-costly life status. The fiddler crabs Leptuca thayeri Rathbun, 1900 and Gelasimus borealis Crane, 1975 were used as model species to evaluate the influence of maternal status on the crabs' thermal limit (TL) under a climate warming scenario. We used a non-invasive method to estimate crabs' heart rates using the endpoint for the heart function as their TL. Environmental characterization showed that the mean temperature experienced by non-ovigerous and ovigerous female crabs was below their TL with some extremes above their TL. Ovigerous G. borealis were more sensitive to warming (lower TL) than non-ovigerous; otherwise, ovigerous and non-ovigerous $L$. thayeri had similar TL. Our model species have similar reproductive behaviour but not the same reproductive pattern: L. thayeri has a seasonal reproduction period and G. borealis breeds during most part of the year. Energy costs involved in a more continuous reproduction strategies may have had a role on the contrast TLs within species. Also, ovigerous L. thayeri have heavier egg masses than G. borealis. Broods accumulate water and $L$. thayeri egg masses may help as heat sink. Based on our environment characterization and TL results, fiddler crabs living inside coastal forests (e.g., L. thayeri) may be less vulnerable to warming predictions and may have favourable environmental temperature conditions to expand their distributions, besides other abiotic and biotic factors. Beyond theoretical approaches to the temperature effects on aquatic animals, we presented the first experimental support on maternal status' TL and their upper thermal windows, showing a non-generalized pattern for an ectotherm group.

Keywords: ectotherms, ovigerous status, thermal limit, thermal tolerance. 